\title{
Removal of large colorectal lesions resected by endoscopic submucosal dissection using a laparoscopic bag
}
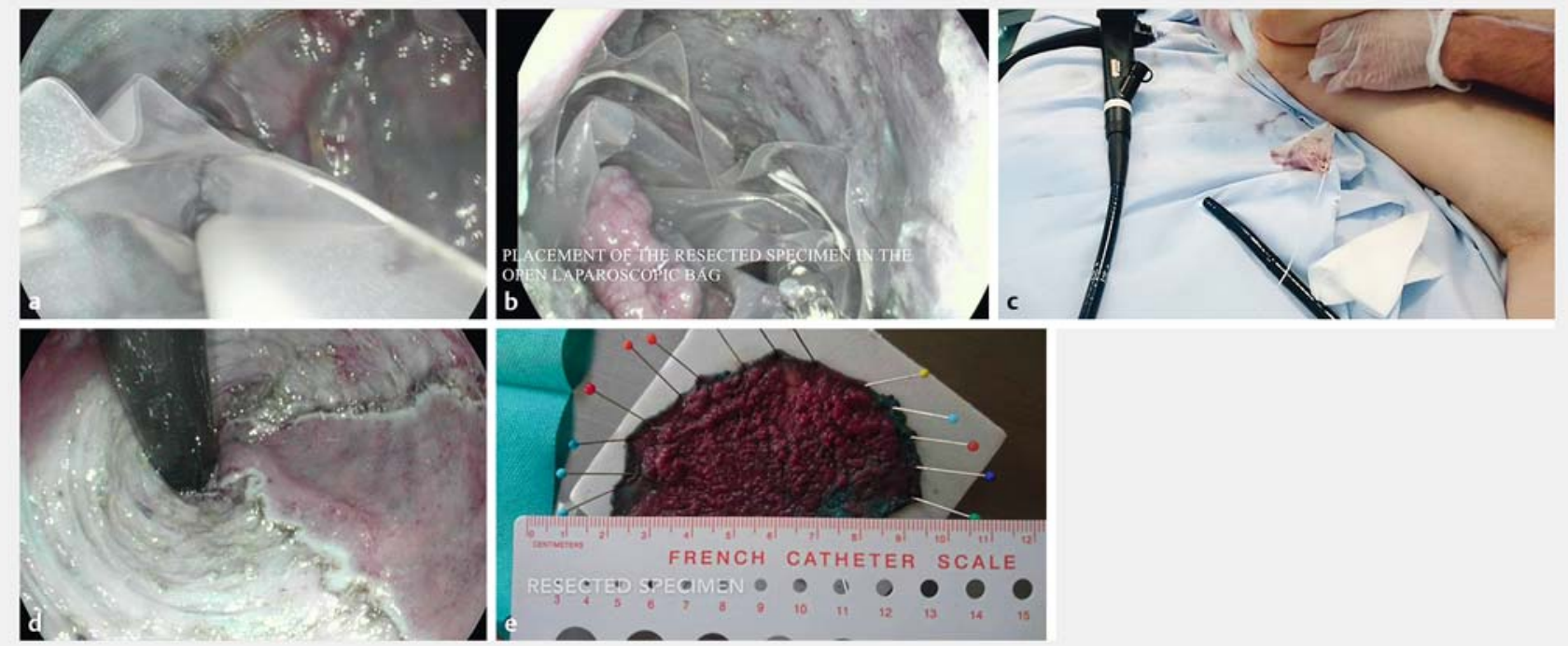

- Fig. 1 Removal of large colorectal lesion resected by endoscopic submucosal dissection (ESD) using a laparoscopic bag. a Open laparoscopic bag in the rectum. $\mathbf{b}$ Placement of the resected specimen in the open laparoscopic bag. $\mathbf{c}$ Retrieval of the specimen inserted in the bag. $\mathbf{d}$ PostESD scar. e Resected specimen.

Colorectal endoscopic submucosal dissection (ESD) has become the standard of care for large superficial colorectal neoplasms, and allows en bloc resection of very large lesions [1].

The first goal of this technique is en bloc and R0 resection of large colorectal lesions to allow good pathological examination and determination of whether the endoscopic resection was curative. Such a conclusion is only possible if the lesion is resected en bloc without damaging the specimen.

For lesions of standard size $(2-6 \mathrm{~cm})$, a basket net is most frequently used to retrieve the specimen. However, the tools available to retrieve larger lesions are often too small, making retrieval of the specimen without damage challenging. Recently, a Japanese team reported an innovative technique known as tumor extraction by defecation (TED) [2]. At the end of ESD performed under conscious sedation, spontaneous extraction by defecation controlled by the patient

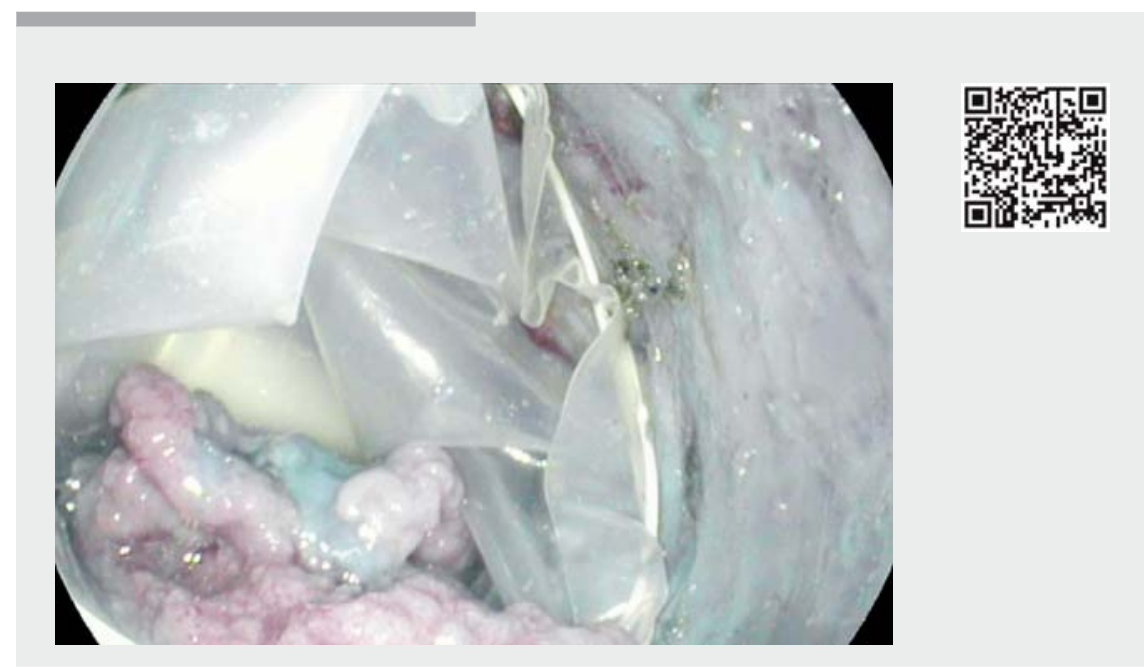

Video 1 Removal of large colorectal lesions resected by endoscopic submucosal dissection (ESD) using a laparoscopic bag. Part 1: End of rectal ESD for large rectal laterally spreading tumor. Part 2: Insertion of the laparoscopic bag into the rectum. Part 3: Good positioning of the bag using large biopsy forceps. Part 4: Placement of the resected specimen inside the open laparoscopic bag. Part 5: Closing the bag by pulling on the dedicated ring. Part 6: Removal of the bag with the specimen inside. Part 7: The ESD scar. Part 8: The resected specimen. 
allows simple extraction of large specimens. However, this technique is not applicable in most European institutions because ESD is generally performed under complete general anaesthesia with mechanical ventilation. This results in a longer wake-up time and a period in the recovery room. We used TED in our institution in three cases; the mean time between the end of the procedure and exit of the recovery room was 80 minutes. Pathological analyses revealed that damage due to ischemia interfered with interpretation of the pathology.

We have developed a new and efficient method for retrieving large specimens using a laparoscopic bag ( $\triangleright$ Fig.1, - Video 1). At the end of the procedure, the laparoscopic bag is inserted into the rectum and opened thanks to the specific delivery method. The endoscope is then reinserted into the rectum and the laparoscopic bag is ideally positioned around the lesion using large biopsy forceps. The lesion is placed into the laparoscopic bag using the biopsy forceps, gravity, or a basket net. Next, the closing line is caught using the biopsy forceps and pulled outside the patient, allowing closure of the bag containing the specimen.

We used this technique successfully in four consecutive cases with large lesions (mean large diameter $85 \mathrm{~mm}$ ), and believe that it facilitates extraction of large colorectal lesions resected by ESD.
Endoscopy_UCTN_Code_TTT_1AQ_2AD

\section{Competing interests}

None

The authors

Jérémie Jacques ${ }^{1,2}$, Abdelkader Taibi ${ }^{3}$, Aurelie Charrissoux ${ }^{4}$, Mathieu Pioche ${ }^{5}$, Paul Carrier ${ }^{1}$, Benoit Chaput ${ }^{6}$, Romain Legros ${ }^{1}$

1 Hepatogastroenterology Department, Limoges University Hospital, France

2 National Center for Scientific Research, XLIM, UMR 7252, Limoges, France

3 Visceral Surgery Department, Limoges University Hospital, Limoges, France

4 Pathology Department, Limoges University Hospital, Limoges, France

5 Hepatogastroenterology Department, Hopitâl Edouard Herriot, Lyon, France

6 Plastic and Reconstructive Surgery Department, Toulouse University Hospital, Toulouse, France

\section{Corresponding author}

\section{Jérémie Jacques, MD}

Service d'Hépato-gastro-entérologie, $\mathrm{CHU}$ Dupuytren 87042, Limoges, France Fax: +33-5-55058733

jeremiejacques@gmail.com

\section{References}

[1] Pimentel-Nunes P, Dinis-Ribeiro M, Ponchon $T$ et al. Endoscopic submucosal dissection: European Society of Gastrointestinal Endoscopy (ESGE) Guideline. Endoscopy 2015; 47: 829-854

[2] Nemoto D, Hayashi Y, Utano K et al. A novel retrieval technique for large colorectal tumors resected by endoscopic submucosal dissection: tumor extraction by defecation. Endosc Int Open 2016; 4: E93 - 95

\section{Bibliography}

DOI https://doi.org/10.1055/s-0043-119977

Published online: 17.10.2017

Endoscopy 2018; 50: E1-E2

(c) Georg Thieme Verlag KG

Stuttgart · New York

ISSN 0013-726X

\section{ENDOSCOPY E-VIDEOS}

https://eref.thieme.de/e-videos

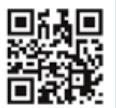

Endoscopy E-Videos is a free access online section, reporting on interesting cases and new

techniques in gastroenterological endoscopy. All papers include a high quality video and all contributions are freely accessible online.

This section has its own submission website at https://mc.manuscriptcentral.com/e-videos 